\title{
CERCO À LIBERDADE: A COMPLEXA DINÂMICA DO PODER NOS EUA
}

CECiLia AZEVEDo*

RESENHA DE: GERSTLE, GARY LIBERTY AND COERCION. THE PARADOX OF AMERICAN GOVERNMENT FROM THE FOUNDING TO THE PRESENT. PRINCETON: PRINCETON UNIVERSITY PRESS, 2015.

Liberty and Coercion: The Paradox of American Government from the Founding to the Present, publicado em 2015 pela prestigiosa Princeton University Press, se impõe como uma obra fundamental para todos os interessados em História dos Estados, como também o são dois livros anteriores do autor - The rise and fall of the New Deal Order (organizado em conjunto com Steve Fraser) e The American Crucible: Race and Nation in the Twentieth Century. Atualmente na Universidade de Cambridge, na Inglaterra, Gary Gerstle é sem dúvida nenhuma um dos maiores nomes da historiografia dos EUA, laureado com os mais relevantes prêmios ao longo de sua trajetória acadêmica no país. Após se notabilizar na História Social, enveredando por questões também caras à História Cultural, como a das identidades coletivas, Gerstle, com o livro em tela, contribui para o ímpeto recente da História Política, especificamente dos estudos sobre as instituições governamentais, tema que não despertou muito entusiasmo nos historiadores de sua geração.

Ao analisar a forma como processos sociais e políticos ao longo do tempo produziram configurações e dinâmicas complexas entre as várias instâncias de poder local e central; executivo, legislativo e judiciário - o livro joga por terra simplificações muito correntes a respeito das relações entre Estado e sociedade nos EUA. Entre elas, a ideia de que da genialidade dos pais fundadores da nação originou-se um regramento legal que, ao restringir a ação do Estado - entendido sempre como poder central -, assegurava que o horizonte de liberdade que se abria aos americanos não fosse ameaçado. Esse modelo teria sido pervertido pelo surgimento, em função de eventos e períodos excepcionais - crise de 29 , duas guerras mundiais, guerra fria - de um Leviatã, Estado central forte, corruptor da verdadeira tradição, identidade e valores americanos.

A primeira parte do livro dialoga com outros autores ${ }^{1}$, que têm buscado des-

\footnotetext{
* Professora do Programa de Pós-Graduação em História da Universidade Federal Fluminense (UFF). Doutora em História pela Universidade de São Paulo (USP).
} 
construir o mito de que o Estado central no século XIX nos EUA era fraco. Afinal, nesse século, o Estado central garantiu a independência contra a Inglaterra, eliminou a resistência e deslocou nações indígenas, promoveu uma expansão territorial sem precedentes, através de acordos (com a França) ou guerra (contra o México), carreou investimento colossal em infraestrutura de transporte e comunicações, enfrentou e venceu o desafio da secessão, implementou uma lei geral de terras. No plano externo, iniciou empreendimentos fora do continente já na década de 1830 através de expedições marítimas de grande porte ${ }^{2}$, culminando com a transformação do país em potência imperial após vitória na Guerra Hispano-Americana, o que Ihe rendeu significativo espólio colonial.

Mas se o Estado central acumulou todos esses êxitos, Gerstle chama atenção para o fato de que a arquitetura jurídico-política interna pouco foi alterada. O livro joga luz então sobre um conceito pouco debatido justamente por ser largamente desconhecido fora dos meios jurídicos: o chamado poder de polícia reservado aos estados.

Tal poder, como se poderia pensar à primeira vista, não diz respeito meramente a áreas como administração da segurança e regulação das atividades econômicas, mas a um âmbito muito mais amplo de ordenamento social, incluindo uso de drogas, direito ao aborto, salário mínimo, direito de organização de trabalhadores, mapeamento eleitoral, assistência a imigrantes, casamento entre raças e pessoas do mesmo sexo, entre outras. Gerstle aponta que princípios de ordem moral e religiosa se faziam sentir em leis que impunham fechamento do comércio aos sábados e domingos e até mesmo a penalização de blasfêmia, vigente em Massachusetts até 1928. Este amplo raio de ação que afetava e ainda afeta aspectos cruciais da vida privada dos indivíduos, impeliu o autor a sublinhar contradições internas ao próprio texto da Constituição americana, além de ver apropriações antagônicas como fonte e efeito de culturas políticas concorrentes.

Desse modo, ao lado da doutrina liberal clássica que enfatizava a necessidade de resguardar o maior espaço possível de liberdade individual frente à ameaça potencial de coerção pelo Estado, é preciso, segundo Gerstle, enxergar uma tradição anta-

\footnotetext{
${ }^{1}$ Exemplo da retomada desse tema entre historiadores, especialistas em história do direito, cientistas sociais e políticos pode ser encontrada em: Sparrow; Novak; Sawyer, 2015

2 JUNQUEIRA, 2015.
} 
gônica que respalda o poder local imiscuir-se em um âmbito extenso da vida social, entendendo que sobre esta esfera não se aplicariam restrições constitucionais supostamente concebidas para limitar unicamente a ação do governo central.

O livro tem o grande mérito de apresentar essa dualidade - ou quase esquizofrenia, se quisermos usar termo mais forte - através de um caso paradigmático: o de terem os estados ficado desobrigados de observar a Bill of Rights até a década de 1960. Esta situação é duplamente extravagante: por sua longa duração e escassa discussão política e intelectual sobre seu significado, que o livro de Gerstle tem o mérito de enfrentar.

Apesar de identificar tendências e inflexões, o autor se posiciona claramente contra leituras que tomam os processos históricos como lineares e irreversíveis. Além da crítica às teses excepcionalistas e ao contraste entre os séculos XIX e XX, na chave fraco X forte, Gerstle percebe que a expansão do Estado central, assim como o alargamento de sentido de determinados direitos não teriam o grau de estabilidade e a perenidade que as narrativas historiográficas mais correntes sugerem, ecoando certo otimismo em relação a uma fórmula de consenso. No sentido contrário, Gerstle identifica como precários os recursos jurídicos utilizados para a um só tempo equacionar conflitos políticos e demandas sociais e sustentar as possibilidades de intervenção e regulação requeridas pelos imperativos das politicas interna e externa dos EUA.

Um sistema tributário eficiente e que contava com amplo apoio social proporcionou recursos suficientes para manter investimentos elevados e consolidar o aparato de segurança nacional no pós-Segunda Guerra, assegurando a liderança dos EUA no "mundo livre". Contraditoriamente, a própria lógica da Guerra Fria promoveu a expansão da intervenção do Estado central na economia, através do uso de três recursos legais muito bem detalhados no livro: o enquadramento das ações do Executivo nas esferas em que há previsão constitucional de isenção das restrições gerais, como é o caso do comércio internacional e da segurança nacional em eventos como guerras e emergências domésticas; a substituição de finalidade, ou seja, usar prerrogativas de regulação e intervenção em áreas específicas como comércio interestadual para outros fins; transferência de recursos e gestão para setor privado operar sistemas e serviços públicos, indústria de armamentos, infraestrutura, pesquisa científica, etc, resultando numa complexa interpenetração entre público e privado. 
Na década de 1960 o Estado central já acumulara recursos financeiros e políticos para pressionar empresas e estados, condicionando concessões, contratos e liberação de verbas à adequação a parâmetros pré-estabelecidos pelo governo federal em setores como assistência social, saúde, reforma urbana e, o mais importante, integração racial, área em que o New Deal de Franklin Delano Roosevelt não tinha conseguido avançar.

A análise da ofensiva da Suprema Corte contra o poder de polícia e a isenção dos estados em relação ao estabelecido pela Bill of Rights é um dos pontos altos do livro. Mas ela só se torna compreensível pela recuperação das decisões anteriores da Suprema Corte em defesa dos direitos dos estados.

Na decisão de 1833 da Suprema Corte no caso Barron X Baltimore estabeleceuse que o reclamante não poderia invocar a proteção da V Emenda da Constituição contra o poder local porque as dez primeiras emendas que compunham a Bill of Rights voltavam-se para coibir abusos do único poder criado pela Constituição, o governo federal, e portanto não se aplicavam aos estados. O Juiz Marshall registra ainda que se os estados assim o decidissem poderiam incorporar a Bill of Rights em suas constituições estaduais. Assumia-se de forma explícita que os poderes locais expressavam de forma orgânica a vontade do povo, devendo ter ampla latitude em sua jurisdição. Como bem observa Gerstle, ficava implícito que se estados quisessem adotar medidas que restringissem a liberdade de uma minoria com base numa maioria poderiam fazêlo. E assim se fez. Os Códigos Negros e o retrocesso em relação ao período da Reconstrução foram chancelados pela Suprema Corte, que aprovou o princípio de "separados mas iguais" no caso Plessy X Ferguson de 1896.

Essa decisão só seria revertida em 1954 com o caso Brown X Board of Education of Topeka. No momento em que o movimento pelos direitos civis de massa iniciava sua ascensão, o entendimento que a Corte chefiada por Earl Warren adotou de forma unânime foi o de que as leis estaduais feriam a cláusula da igualdade de proteção da XIV Emenda à Constituição.

A cláusula do devido processo também passaria a ser utilizada de modo a exigir que os estados respeitassem direitos não nomeados, mas compreendidos como implícitos ao sentido amplo de liberdade consagrado na Constituição. O direito à privacidade, evocado então, decorreria da necessidade de proteger a liberdade de todos para 
escolher cônjuges, decidir por ter ou não ter filhos, de educá-los de acordo com qualquer religião ou nenhuma, etc. Com tal embasamento seriam derrubadas leis estaduais que impediam o casamento inter-racial (caso Loving $X$ Virginia), impunham oração nas escolas públicas (caso Engel $X$ Vitale), por exemplo.

Prevalecia, assim, a corrente defensora da historicidade da Constituição, ou seja, o entendimento de que a interpretação constitucional deveria ser conduzida em função do contexto e não ser pautada pela intenção original dos que a redigiram. Mas no mesmo sentido Gerstle não deixa de sublinhar o quanto decisões judiciais dessa magnitude não derivaram apenas da compreensão técnica de indivíduos em posições de poder, mas das pressões sociais e políticas sobre as instituições e condições históricas mais gerais.

A discussão sobre direitos evidentemente não era algo transcendente, mas integrante de uma arena, um campo de disputas político-ideológico. Claramente guiado por essa percepção, o governo federal buscou instrumentalizar movimentos sociais em seu intento de submeter o poder dos estados. Segundo Gerstle, numa interpretação bem distinta da usual, o estímulo aos movimentos sociais para disputar espaços de poder no plano local, especialmente no caso de programas de ação comunitária no âmbito da Guerra à Pobreza, não foi efeito indesejado, mas premeditado, em consonância com a estratégia mais ampla dos setores liberal-left que associava garantia e ampliação de direitos civis, dos direitos políticos e do welfare na década de 60.

Mas conforme o próprio título do livro indica, a paradoxal convivência entre liberdade e coerção se manteve. No contexto mesmo de expansão do poder central em detrimento do poder de polícia dos estados, assistiu-se à consolidação e expansão do aparato de segurança nacional agindo dentro e fora dos EUA, através de agências federais e estatutos que Ihes concediam amplas possibilidades de ação. Aliás, desde a Primeira Guerra Mundial até a Guerra do Iraque, leis de exceção têm cerceado direitos e liberdades: Espionage Act (1917), Sedition Act (1918) Alien Registration Act (1940), Smith Act (1940) e o recente Patriot Act (2001) cujos efeitos, embora reduzidos, ainda vigoram, revelando contradições não ocasionais, mas estruturais.

Uma vez que questões relativas a direitos individuais e coletivos, abrangência e responsabilidades em relação ao sistema de bem-estar social e possibilidades de ação do governo federal não foram inscritas no texto constitucional na forma de emendas, 
mas equacionadas de forma precária, conforme defende Gerstle, as batalhas políticas e legais continuaram.

Como é sabido, dos anos 1980 em diante a crítica incessante às interferências e regulações do governo federal e a invocação do direito dos estados por parte de setores conservadores identificados com o Partido Republicano reacendeu sensibilidades políticas profundas conquistando apoio popular e invertendo tendências anteriores. Com Reagan, o redesenho e cortes no sistema de welfare começaram a ser feitos, ampliando-se igualmente a autonomia dos estados na gestão de programas. Mais recentemente, todos os obstáculos ao Obamacare, antes mesmo da eleição de Trump, podem servir como ilustração das possibilidades da reversão do peso relativo do governo federal indicadas por Gerstle. O programa, mesmo desidratado, sofreu resistência no Legislativo, na Suprema Corte e em estados que preferiram abrir mão de recursos financeiros antes tão eficazes como instrumento de imposição do poder federal.

Os embates em torno da imigração também revelam a incessante tensão entre esferas de poder. Disposições legais draconianas anti-imigração em estados como Califórnia e Arizona foram derrubadas pela Suprema Corte, mas, por outro lado, a persistência até hoje de condados, cidades e estados que insistem em adotar políticas de não cooperação com o governo federal de modo a tentar evitar deportações de refugiados e imigrantes revelam a possibilidade de fazer efetivamente do poder local um espaço de resistência cidadã, horizonte mencionado, porém não privilegiado por Gerstle.

De todo modo, tais exemplos atestam o quanto prerrogativas e limites para o exercício do poder não podem ser pensados e equacionados fora das marchas e contramarchas da história, tese central de Liberty and Coercion. Em tempos de agudo dogmatismo, afirmar a historicidade dos fenômenos é tarefa indispensável.

\section{REFERÊNCIAS}

JUNQUEIRA, Mary Anne. Velas ao mar: US. Exploring Expedition (1838-1842). A viagem científica de circum-navegação dos norte-americanos. São Paulo, Intermeios/Fapesp, 2015.

SPARROW, James T.; NOVAK, William; SAWYER, Stephen W. (eds). Boundaries of the State in US History. Chicago/London: University of Chicago Press, 2015. 